\title{
Research and Development of Accounting Management Information System for Railway Enterprise's Fixed Assets
}

\author{
Lei Ma \\ IT Department, China Academy of Railway Sciences Corporation Limited, Beijing, China
}

\section{Email address: \\ 1514303594@qq.com}

\section{To cite this article:}

Lei Ma. Research and Development of Accounting Management Information System for Railway Enterprise's Fixed Assets. Science Journal of Applied Mathematics and Statistics. Vol. 7, No. 5, 2019, pp. 79-82. doi: 10.11648/j.sjams.20190705.13

Received: August 30, 2019; Accepted: October 21, 2019; Published: October 23, 2019

\begin{abstract}
In order to deepen the whole-course management of fixed assets accounting of railway enterprises and promote the optimal allocation of enterprise resources, it is particularly necessary to establish a whole-course management system of fixed assets accounting for railway enterprises. Aiming at the problems exposed in the application of fixed assets accounting and management in railway enterprises, this paper investigates and summarizes the needs of enterprises, and puts forward the design scheme of railway enterprises fixed assets accounting and management information system. In this paper, based on the concept of the whole process of fixed assets management accounting of railway enterprise, promote the optimized allocation of enterprise resources, the use of computer network and information technology, through the optimization of business processes control mechanism, establish a data set, design a whole process of fixed assets of the enterprise railway management information system, solve the problem of application in the accounting of fixed assets management in railway enterprises. The multilevel network of railway enterprise management department is realized to meet the fine management requirements of different management levels.
\end{abstract}

Keywords: Railway Enterprises, Fixed Assets Accounting, Whole Course, Information Systems, Software Development

\section{Introduction}

Fixed assets are not only the material basis for enterprises to survive, but also the source of enterprise benefit switch are related to the operation and development of enterprises. Scientific management and correct accounting of fixed assets in enterprises are conducive to promoting enterprises to correctly evaluate the overall situation of fixed assets, improve the efficiency of assets, reduce production costs, realize the preservation and appreciation of assets and enhance the comprehensive competitiveness of enterprises.

With the improvement of management requirements and the development of information technology, the railway related system gradually had some problems such as data concentration control mechanism is not sound, the management of the business process is not fully covered, business cooperation and internal control mechanism is very weak. The data are also difficult to meet the needs of decision analysis, technology and function of support is insufficient. All these problems restrict the development of the information of railway fixed assets [1].

Full lifecycle management of equipment is divided into three phases, including early management, operation \& maintenance, and scrapping.

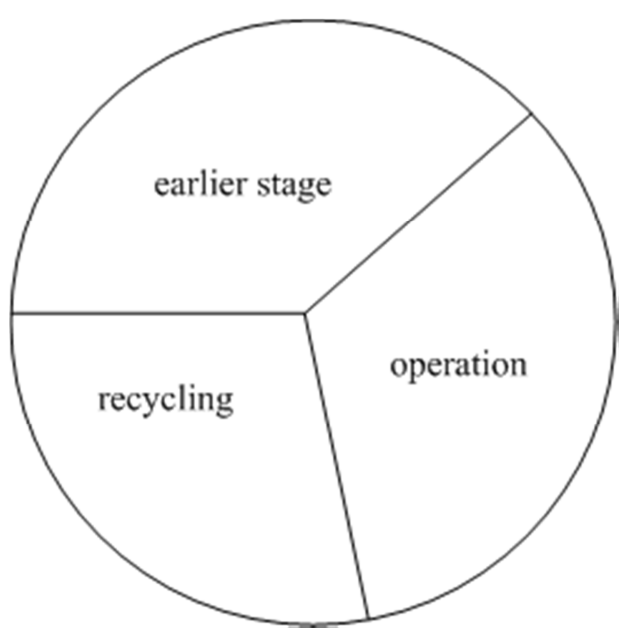

Figure 1. The Full lifecycle management of equipment. 
Early management mainly covers planning for equipment procurement, bidding, type selection, procurement, acceptance of incoming goods, installation and commissioning. In the phase of operation $\&$ maintenance, the management mainly covers routine maintenance, inspection, monitoring, diagnosis, repair and updating of equipment, in an attempt to ensure equipment is often in good technical conditions during their operation. In the phase of scrapping, efforts are mainly made to scrap and recycle equipment which reaches the end of their service life, malfunctions frequently, requires much cost for repair and still fails to meet technical requirements after repair, to end the service of equipment [2].

\section{Objectives of System Construction}

In railway enterprises, the information system of fixed assets accounting whole-process management is based on total assets life cycle management idea. Using computer network and information technology, it focuses on optimizing business processes, setting up data centralized control mechanism, promoting data sharing and internal control, strengthening management decision analysis, to realize multistage network fixed asset management applications of the railway enterprise financial management departments at all levels and satisfy the refined management demands of different management levels [3].

\subsection{Strengthen the Value Management of Fixed Assets and Effectively Promote Physical Management}

By standardizing the parameters and standards of fixed assets accounting, the dynamic business at the front end of fixed assets accounting will be promoted to a standardized path, the value management of fixed assets will be strengthened and the standardized management of fixed assets can be effectively promoted which help to realize the consistency of accounts and facts.

\subsection{Full Coverage of Business to Achieve the Whole Process of Management}

Realize the value of each link of fixed assets management, including the new addition, transfers, sales, investment, lease, inventory, donation, maintenance, commission, scrap, disposal and satisfy the whole business management needs of fixed assets utilization, dynamic management, subsequent expenditure management, inventory and information disclosure and realize the whole process management of fixed assets from new add to scrap and disposal to provide the foundation for realizing the full cost analysis and the whole process control of fixed assets [4].

\subsection{Optimize Business Process and Improve Work Efficiency}

Through system construction, to further promote and support the optimization of fixed assets accounting business process and constantly improve the fine management level of fixed assets accounting. Using new technologies and adopting new architectures, a fixed asset accounting and management system with complete functions, friendly interface and business interconnection is formed to improve work efficiency.

\subsection{Implement Effective Internal Control and Standardize Accounting Management}

By standardizing the business process and technical standards, to further strengthen the ability of information management and control. And integrate the internal control system into the it and submit key processes and links to the system control according to the requirements of the internal control system of finance and accounting, to realize the whole process internal control and standardize the accounting and management of financial internal fixed assets.

\subsection{Support Business Decisions and Improve Economic Performance}

Make use of the corresponding points, lines and planes on the electronic map to realize the comprehensive visual display of fixed assets' distribution and positioning, correlation analysis, asset status and other information; Through the multi-dimensional and multi-angle query statistics function to realize financial analysis and other decision-making support information, enhance the effectiveness and scientific management decision, to improve economic benefits [5].

\section{Core Business Analysis}

Through sorting and optimizing the business process, to realize the online audit process of the whole business including new addition of fixed assets, card revocation, information change, allocation, investment, rental, donation, entrustment, maintenance, inventory, value adjustment, additional depreciation and depreciation provision [6-7].

It also helps realize the automatic flow of cross-unit business data in the system, ensure the consistent effectiveness of business data, realize the traceability of each link audit process and promote the standardization of financial personnel management; and the internal control of fixed assets accounting management is enhanced by putting the control of key business links into the system [8].

And by providing function of fixed assets electronic accessories maintenance and online preview, the management of assets electronic archives and electronic basis management and traceability of all dynamic business can be realized and it can realize business processing functions such as entrustment, sale, lease, maintenance (including capitalization of overhaul), donation and disposal of fixed assets, so as to meet the requirements of the whole process management of fixed assets; And by providing the maintenance function of primary and secondary card, the management of asset allocation relationship is realized, also relevant financial forms can be automatically generated and 
support multi-format printing and exporting can be supported through various functional business data; And by providing the visual display function of asset map, railway enterprises can fully grasp the data of fixed assets.

\section{Technical Architecture of the System}

The construction of the system is completely based on the
B/S (browser/server) structure [9], it adopts the JAVA development language and the designing of the front and rear end separation and also provides application support services to business applications in the form of various service components. Through component technology, the system provides flexibility, scalability and other support to adapt to changes in business requirements [10].

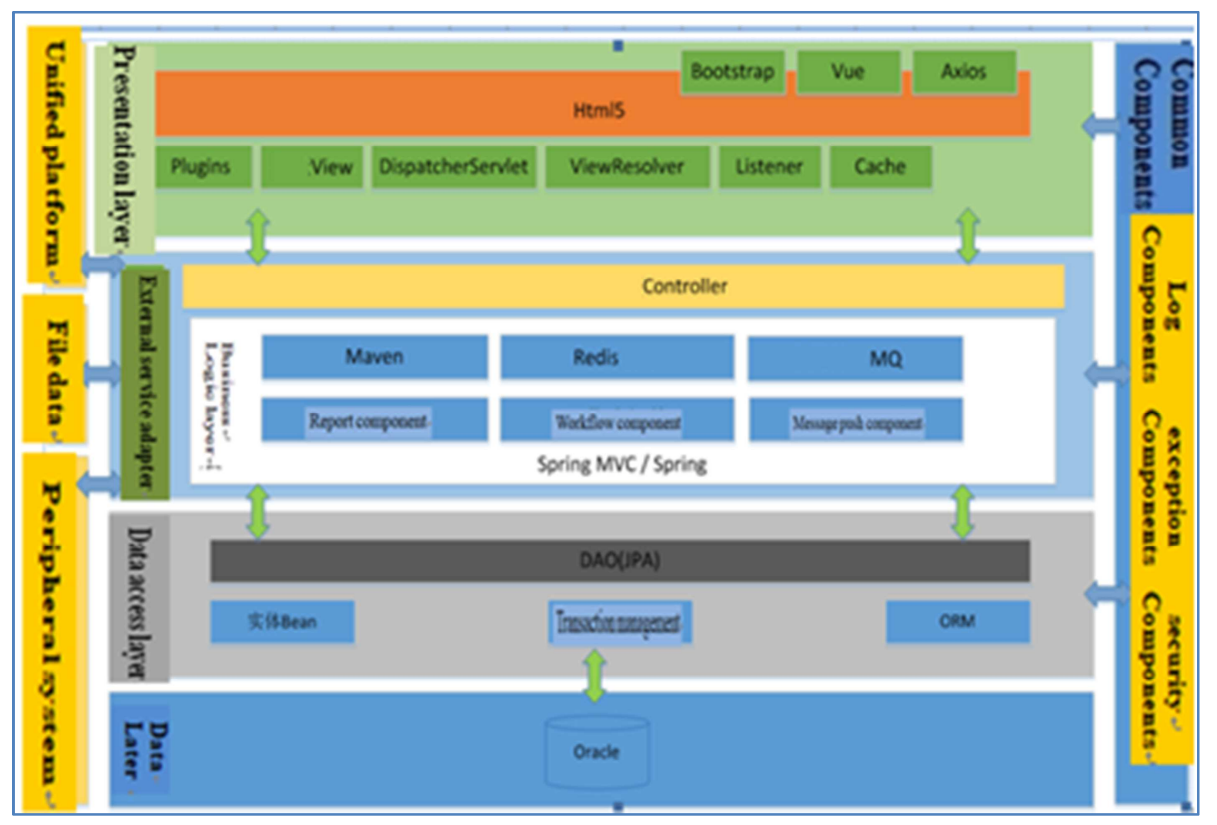

Figure 2. Structure of System.

\section{Functional Design of the System [11]}

\subsection{My Workbench}

It mainly includes to deal with the backlog task, inquiry about completed tasks and the early warning prompt, the announcement, the system helps and the miniature cockpit. [12]

\subsection{Application and Dynamic Management}

It mainly includes the information maintenance and approval of dynamic business documents such as fixed assets' new addition, allocation, temporary appraisal and transfer to the official account, allotting, sale, investment, lease, donation, scrap, disposal and entrustment, etc. [13]

\subsection{Card Management}

It mainly includes the functions of card revocation, card information alteration, status and use place alteration, etc. to realize the processing of card information alteration and revocation registration.

\subsection{Maintenance Management}

It mainly includes asset maintenance and overhaul back, to realize Maintenance of asset maintenance information and the capital treatment of asset overhaul.

\subsection{Accounting Management}

It mainly includes the functions of value adjustment, normal provision for depreciation, depreciation allowance for individual assets, depreciation rush back, depreciation allocation, impairment provision and month end carry-over. And through modeling to achieve fixed assets fine accounting. [14]

\subsection{Statistical Analysis}

Provide multi- angle and multi- dimensional statistical data and support the export of statistical results. it mainly includes statistics of change records, statistics of scrap assets, statistics of over age assets, statistics of depreciation assets, statistics of overhaul assets, statistics of dynamic assets, statistics of asset impairment records, statistics of asset depreciation records, statistics of idle assets, etc.

\section{Conclusion}

In the railway enterprises, the construction of fixed asset accounting whole-course management information system has met the latest demand of railway enterprises' fixed asset accounting whole-course business. Through component technology, the system provides flexibility, scalability and other support to adapt to changes in business requirements. 
It has improved the level of system construction and greatly improved the status stable of railway enterprises, such as fine accounting of fixed assets, centralized data control, financial internal control standard and electronic archives management, etc, which is of great significance for railway enterprises to strengthen operation and management.

\section{References}

[1] Notice on the issuance of "measures for the management of fixed assets of China railway corporation" (China railway general finance [2015] no. 45)

[2] Railway transport equipment overhaul management measures (railway finance [2011] no. 198).

[3] Special planning for railway financial accounting management information system (finance and accounting [2010] no. 27).

[4] Standards for enterprise accounting information (finance and accounting of ministry of finance [2013] no. 20).

[5] Basic requirements for network security level protection of information security technology (GB/ t22239-2019).

[6] Wang Junqiang. Research and Implementation of Equipment Management Information System Based on Component [M]. Computer Integrated Manufacturing Systems, October 2004 (9).
[7] Qin Jianhua, Huang Shijie. Development of Equipment Management Information System [M]. Computer Applications, 2001, 21 (zl).

[8] Xiong Guanghua. Frame Design, Technical Implementation Pattern and Application of Equipment Information Management System [M]. Journal of Wuhan Engineering Institute, 2007, 19 (1).

[9] Jia Xiuping, Zhang Guanghui, Meng Lili. Plant Management Information System Based on $\mathrm{B} / \mathrm{S}$ Model [M]. Plant Maintenance Engineering, 2008 (9).

[10] Chai Yongsheng. Research on Equipment Management Information System [M]. Computer Engineering and Applications, 2014, 40 (12).

[11] Jiang Feipeng. Design and Implementation of Management Information System for EMU's Maintenance and Repair Equipment [M]. Railway Computer Application, 2011, 20 (2).

[12] Wang Wei. Workflow-based Design of Equipment Management Information System [D]. Jiangsu Science \& Technology Information, 2014 (20).

[13] Jiang Zhiqiang. Development and Application of Equipment Management Information System [D]. China Plant Engineering, Beijing, 2011.

[14] Pekka Leviäkangas. Service Value and Componentized Accounting of Infrastructure Assets [J]. Journal of Infrastructure Systems: 